DOI: $10.19195 / 2084-5065.44 .8$

\title{
Testament examination
}

\author{
PÀvlos KipourÀs \\ Università Telematica Pegaso \\ Scuola Forense di Grafologia, Naples, Italy
}

One of the most popular cases in document examination refers to Testaments. Writing the last will usually happens when the testator realizes that the end of his life is imminent. Because of the fact that the clinical condition of the testator is often aggravated, we expect to find in the text particular indicators of the hand's difficulty to write. This factor often creates several distortions in the person's normal handwriting, such as tremor, lower flexibility of the hand and a general deterioration of its skill. It is always very important to be informed about the clinical condition of the testator and eventual other particular details about the historical moment of the testament's graphic procedure, because, apart from the clinical situation, the body's posture, the medication or an exceptional fact could have affected the usual handwriting.

Regarding the importance of available information, in the following case we have the testament of the father of 92 years old presented by the younger of 2 sons. 40 days after the death of the father, the mother also died at the age of 89 years old.

Two months later the will of the mother is presented to the court, and although seems of different handwriting, it strangely refers to the same date, as if the parents have made their homework by writing the wills on the same day. Apart from this, the text, which has the form of the official language of an attorney not compatible with both parents' 
cultural and linguistic status, is completely the same, word to word, as if the one will was the copy of the other. The only thing that changes is the name of the heir. The father refers to his wife but, ironically, the mother refers to her...wife too!!! Even in this case the handwriting reflects a much more flexible hand than the real mother's graphic skill. This historic fact, not known at first, confirms the initial graphological conclusion about the forgery of the father's will.

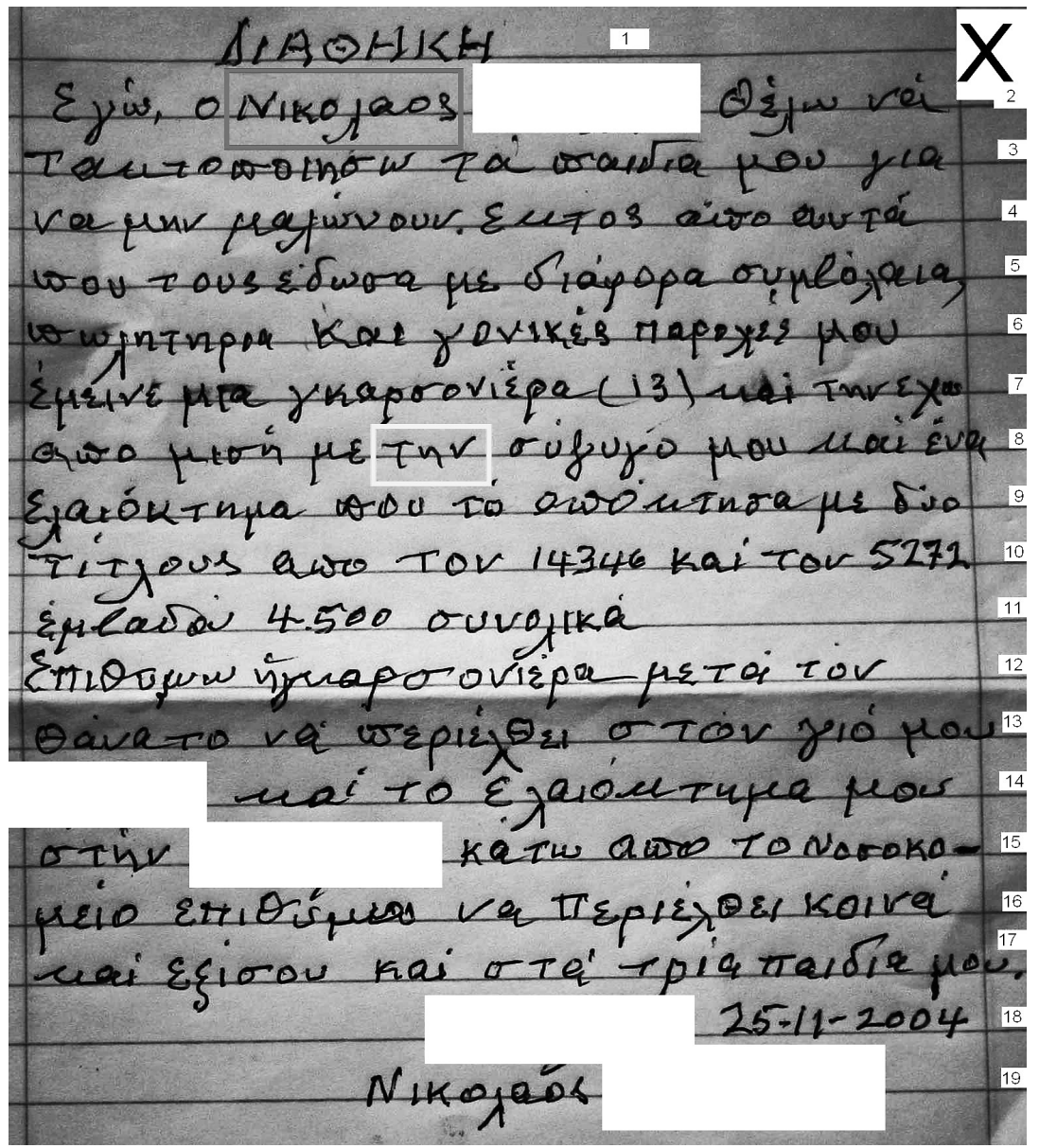

Nowa Kodyfikacja Prawa Karnego 44, 2017

(C) for this edition by CNS 


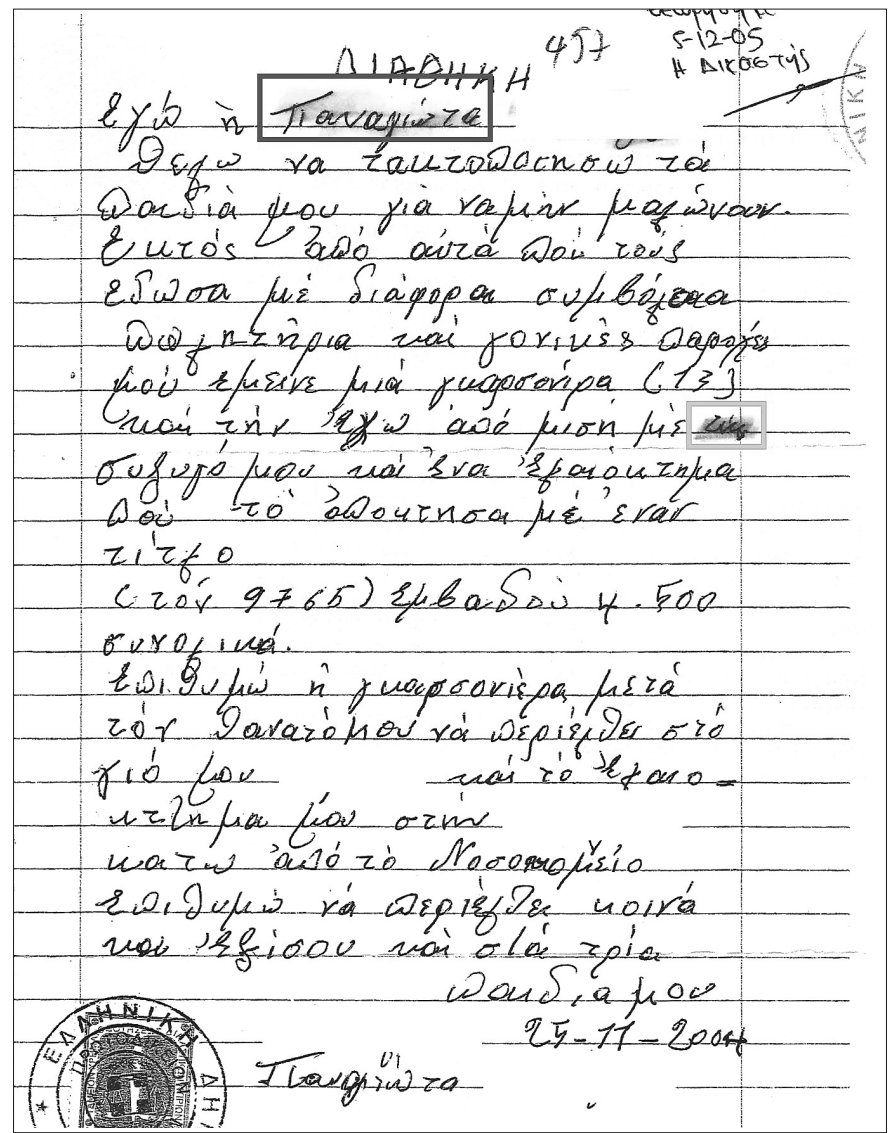

Another very important factor is the age of the testator, because of the fact that it is not so common for young people to write down their last will. Usually, in the case of forgery, the forged document is produced by a person much younger than the original testator. That means that the forger is trying to reproduce the problematic writing of an ill and/or elderly person, imitating the morphological aspect of the letters of the genuine hand. In most of the cases, the forger is not capable of identifying the quality of the strokes and he is trying to reproduce the letters only in their formal aspect, as if he was 'painting' the letters. As a consequence, we expect to find several abnormal and heterogeneous characteristics, because of the fact that the forger cannot pay $100 \%$ attention to every point of the forged docu- 
ment, and that is why in different points of the text the result of the imitation could be more or less effective. In this forged document we usually identify lack of natural and spontaneous writing, because each stroke is not a direct product of the genuine mind, but the result of an effort of imitation by a younger person who has not himself experienced the negative results of clinical problems in his handwriting. Apart from it, the forger tries to reproduce the genuine writing following the procedure in the opposite way. The genuine writing is produced as a result of the order originated by the brain. This order, using the neuromuscular system and the brain's stabilized form of the letters, gives birth to the graphic procedure, which is reflected in the final form or 'image' of the letters. The forger has to follow this procedure heading from the end to the beginning, which means that he is trying to recreate the font of the letters by imitating their shape, in order to arrive to the writing's mental source. As a result, he tries to perform a procedure without having the same 'technical' tool, the original brain, without using the same 'software'. That is why it's difficult for him to be successful and that is why he can't be so effective in every point of the forged text, because he uses different 'software' (his and not the original brain) and different 'printer', a different neuromuscular system.

There are many studies and experiments regarding the effects of the common illnesses of the elderly people which indicate the particular negative results in their handwriting. Except this, we should know that the deterioration of the hand's skill usually becomes more intense after the age of about 55-60 years old, because of the expected effects of ageing. The deterioration of flexibility, elasticity and capacity of the neuromuscular system affects the handwriting, which is a direct representation of the condition of the muscular system. Prof. Alberto Bravo (Italy) has indicated 11 successive phases of the deterioration of the hand's skill called 'phases

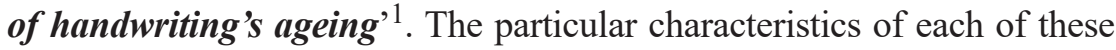
phases are directly connected to the hand's ability and they are extremely useful as indicators in the case of a testament's graphological examination. The most important part of it is the fact, that because of the uniqueness of every person (which is directly connected to the uniqueness of the DNA),

1 A. Bravo, Variazioni naturali e artificiose della grafia, Libreria “G. Moretti”, Urbino 1998, pp. 37-46; A. Bravo, Variazioni naturali e artificiose della grafia, Libreria Moretti Editrice - Urbino, Sulla rota del sole, Giordano Editore, Mesagne, 2005, pp. 48-58. 
these phases do not appear at the same age in every person and they do not present the same chronological duration, because of the fact that the evolution of the hand's skill is unique for everyone and is also connected to his clinical and personal history. It is very important to clarify that these phases always arise in the same sequence, although they may have different time duration in every person. Having in mind these phases and having in hand genuine documents of the testator's hand, we are able to understand if the questioned testament is correspondent to the genuine hand's skill in a certain historical moment. We have to point out that these 11 phases represent and indicate graphical characteristics which are irreversible. That means that the appearance of characteristics of a certain phase makes it impossible for the characteristics of a previous phase to appear again in a person's handwriting, because of the fact that they are the direct result of the deterioration of the hand's graphic skill, in accordance with ageing.

Referring to a particular case, we have a case of a person who seems to have written his will at the age of 80 . The events indicate that on the day referred to the text (5.3.2007), he was carried by the ambulance to the hospital very early in the morning (about 6.a.m.) in a comma, and he stayed in the Intensive Care Unit (ICU) for several days. This fact makes it impossible for him to have written a will and, in addition to that, we find elements indicating a much more flexible hand. These are the points of the text where the forger paid less attention.

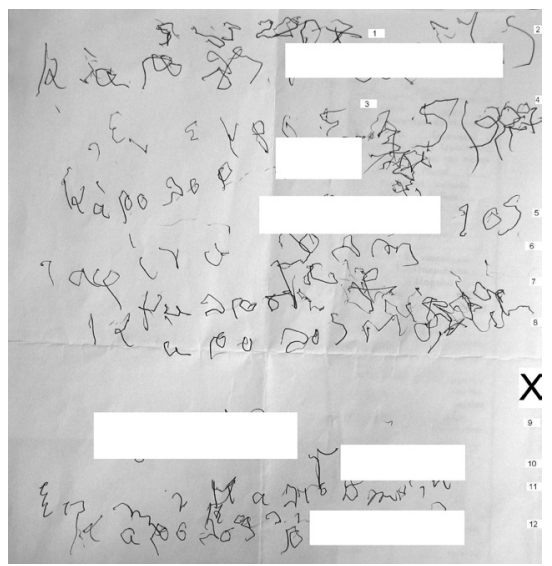


Although the general appearance of the text gives the impression of a hand having difficulty in writing, particular aspects of several letters indicate much more flexibility. As a first impact, we can see that the upper part of the testament seems more problematic, and in that part we cannot even understand how the writer separates the letters, the words or even the different rows of the text.

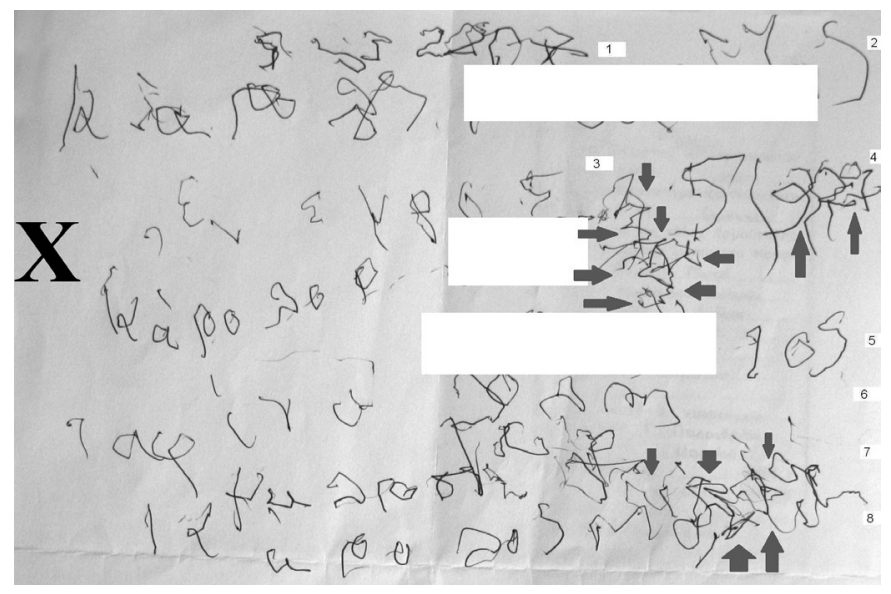

The most clearly recognized phrases or words regard the name of the testator and the name of the heir, while there is no particular reference to the heritage. In the end of the text, where the forger pays less attention, confident of the successful forgery, we find some strokes drawn with surprising flexibility. The most characteristic point is the letter ' $\tau$ ' in row 9 and the contradiction in the combination of the letters «бo» in row 12.

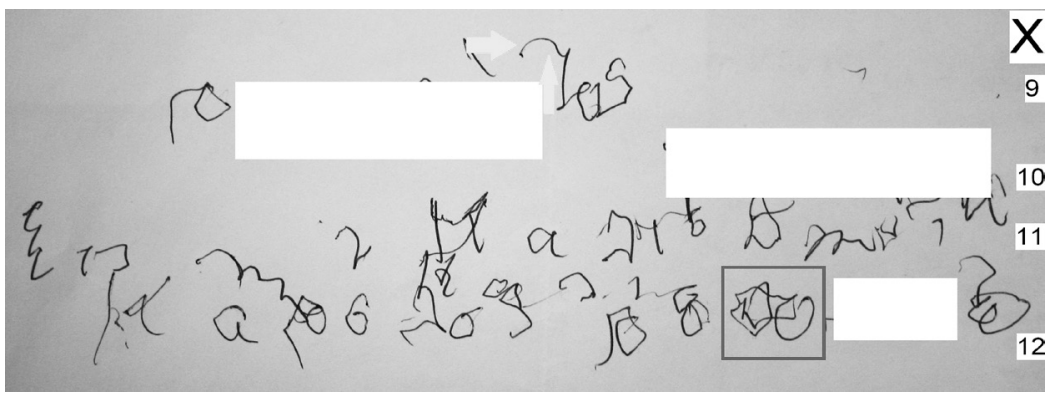



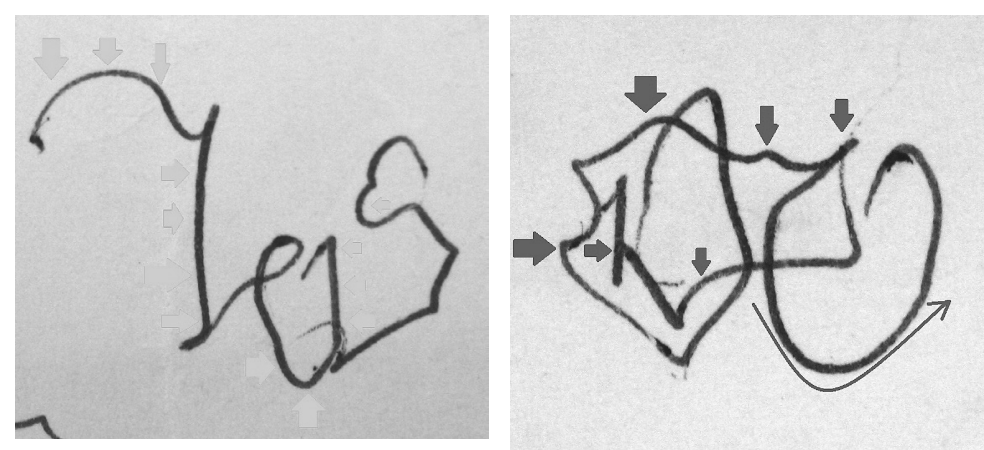

The forged testaments are usually reproduced by people close to the testator who have lived with him/her during their last period of life. In many cases, the forger tries to create the conditions that indicate, as a result of the historical events, the authenticity of the testament. Usually, they try to conceal their participation, mainly based on the facts, because they understand subconsciously that the perfect imitation of a testament is impossible. Whether the forgery (not only as a graphic product but as a whole historical event) will be successful or not, very often depends on how much time the forger had at his disposal in order to organize the facts, because a well based historical scenario usually justifies the problematic points of a less successful forgery. It is always a particular aspect of the forged document that indicates that it is not a genuine one, but the construction of real facts in real time that justify the problematic points of the forged documents can 'heal' the graphic differences. Very often, the forger tries to write a small text in order to avoid being identified. An extended text is less common and usually it is the result of a very self-conscious or a very capable forger, or even less intelligent. In any case, the forger cannot be $100 \%$ successful in his attempt and very often the lab analysis is enough to indicate the forgery without arriving to the graphological analysis of the document's examination, as for example in cases where a particular kind of pen or paper did not exist in the date referred to in the text. The success of the attempt also depends on whether the forger has to fill a part of an existing text or has the opportunity to produce the whole text. In the last case, he has the time to practice and recreate several documents, which gives him the chance to choose the best of his attempts and use it as the official (forged) will. 
In the following example, we have the text of a will which was left incomplete. The testator's companion found this unfinished will after his death and she tried to complete the text in her favour, against the daughter. The result is very interesting, regarding the morphological aspect of the handwriting.
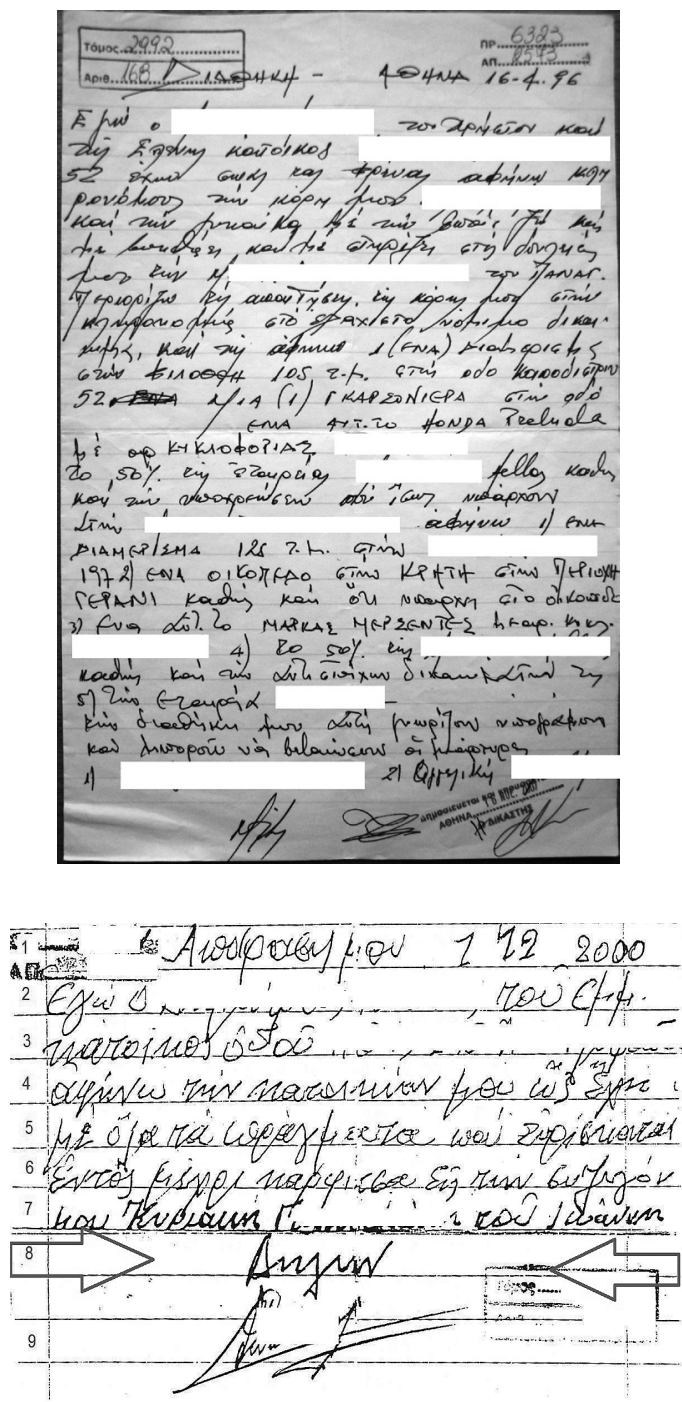

Nowa Kodyfikacja Prawa Karnego 44, 2017

(C) for this edition by CNS 
Another interesting point of this will is the fact that, although the Law does not demand the confirmation of the content of a will by testimonies, in this case there is a reference to two persons, although we find the signature of only one person next to the testator's.

In the following case the testator seems to have written the whole text alone but not in the same time as we can understand from the lab inspection of the original document. Several parts of it seem to have been written in different lapses of time, since we can see different colors of the pens' ink, which is visible even without particular lab examination. Even from the photocopy we can notice parts of the text with different intensity of the strokes, especially in the lower part of the text.
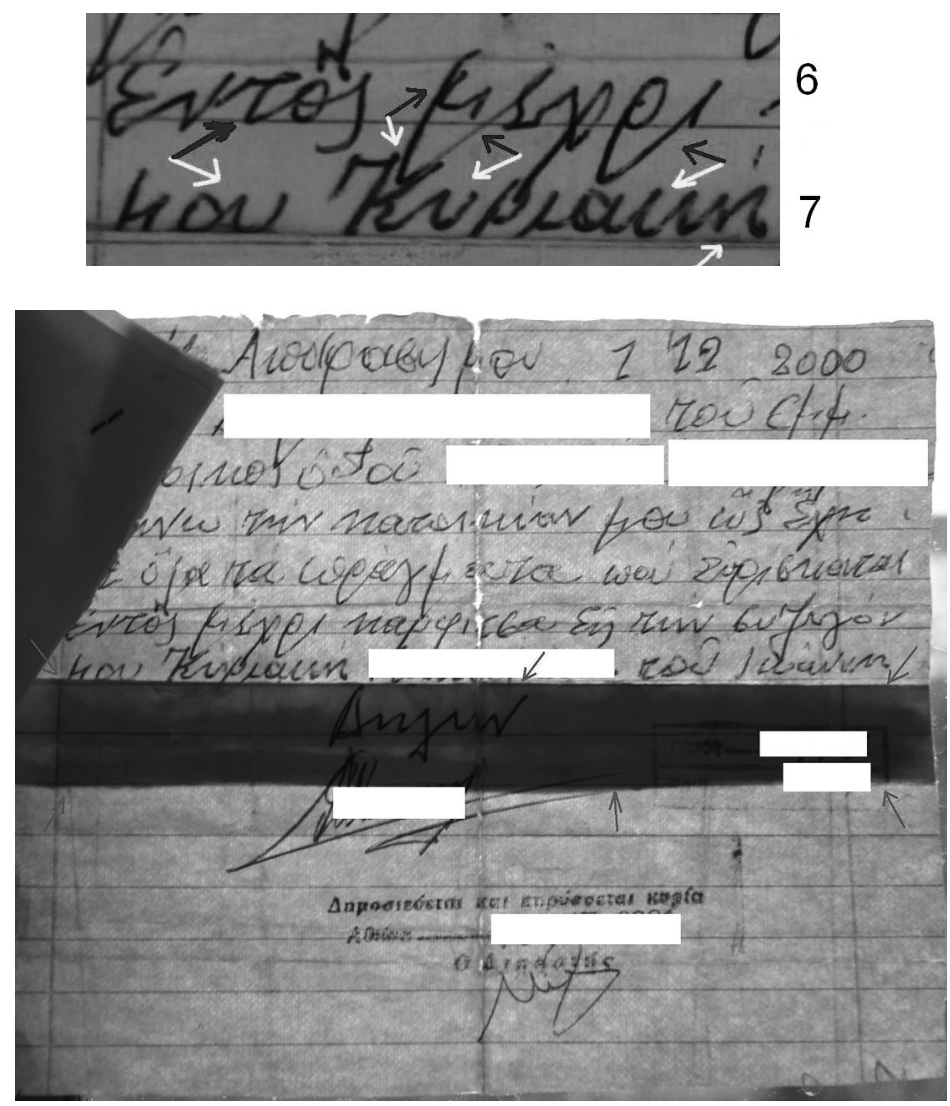

Nowa Kodyfikacja Prawa Karnego 44, 2017

(C) for this edition by CNS 
In that point in the original document we notice two different pens with different blue ink colors, in the rows 6 and 7 .

We notice a kind of 'collage' made by using 2 pieces of paper from the same notebook. Reflecting the sun's light in the back part of the paper, the collage is easily visible and spectacular.

As we can see, we find the collage after row 7, which means that row 6 is written in the same paper with a different pen, which is also different to the pen of the final 2 rows. In addition, the color of the ink is different in the date ' 1.12 ' of row 1 , and the graphic skill appearing in the writing of the year '2000' indicates less tremor.

The dynamic aspect of the handwriting indicates different phases of the procedure of the 'handwriting's ageing', and we can see that the signature as a formal aspect demands a quite flexible hand. In the point of writing ' 1.12 ' of the date, the hand does not seem to have the same skill, the same stability and the same graphocinetic capacity, due to the aggravation of the testator's clinical condition.
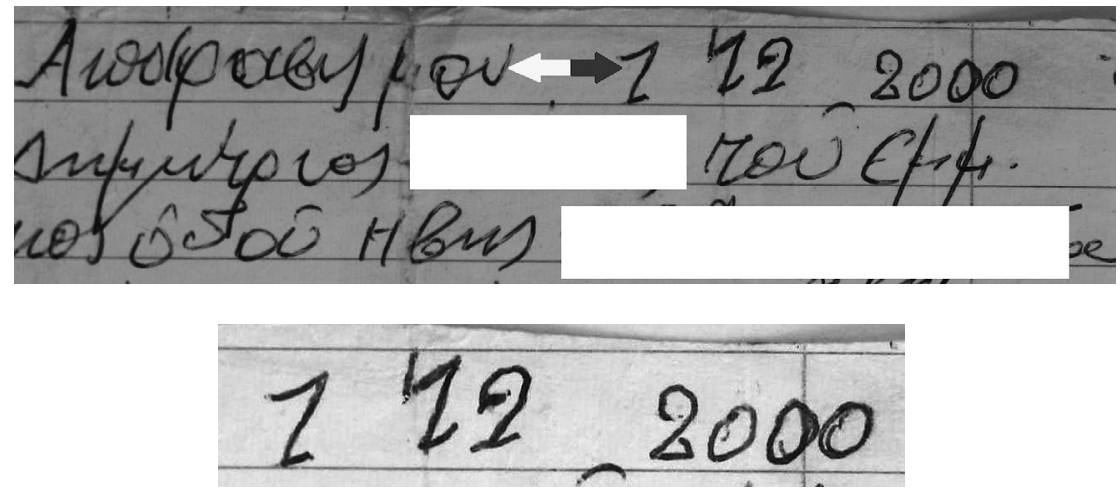

Another eventual problem is the case of guided or assisted hand.

As a conclusion, when we examine a testament we must always be very careful to the historical information we can collect, to the clinical condition of a person as shown by medical documents, and to the testator's age. This puzzle of information along with the lab analysis specify the basis of the dynamic approach of the graphic stokes of the whole text, indicates the compatibility or not of the graphic skill of the hand that has written the testament in exam, and leads to a well justified conclusion. 


\section{References}

Bravo, A., Variazioni naturali e artificiose della grafia, Libreria "G. Moretti", Urbino 1998.

Bravo, A., Variazioni naturali e artificiose della grafia, Libreria Moretti Editrice - Urbino, Sulla rota del sole, Giordano Editore, Mesagne 2005.

\section{Summary}

The testament's examination should be methodologically approached very carefully by the document examiner. He has to take into consideration the clinical condition of the presumed testator, the particular historical circumstances of the testament's production, and information regarding the age of the writer and his personal history. Presentation of different cases with particularities which could orientate the investigation's hypothesis and lead to the right conclusion.

Keywords: brain, chronological, forger, forgery, ink, irreversible, lab, morphological, neuromuscular, phase, scenario, software, testament, testator. 